\title{
Sinema Terapi: Aile Danışmanlığı Alanında Sinema Terapi Çalışmalarının İncelenmesi
}

\author{
DOI: 10.26466/opus.687535
}

\author{
* \\ Ferhat Bayram* - Eyyüp Özkamalı ** \\ * Uzm. Psikolojik Danışman, Milli Eğitim Bakanlığı, Şanlıurfa/Türkiye \\ E-Posta: ferhatbyrm@gmail.com \\ ORCID: 0000-0002-1711-7884 \\ ** Dr. Öğretim Üyesi, Gaziantep Üniversitesi, Eğitim Fakültesi, Gaziantep Üniversitesi/Türkiye \\ E-Posta: ozkamali@gantep.edu.tr \\ ORCID: 0000-0003-3534-018X
}

\section{Öz}

Bu makalenin amacı sinema terapi alanında Türkiye'de ki aile danışmanlığında kullanılan filmlerin incelenmesi ve değerlendirilmesidir. Yapulan araştırmada doküman analizi ve sistemli tarama yöntemleri kullanılmıştır. Araştırmanın kriterlerini karşılayan toplamda 7 adet çalışmaya ulaşılmış ve ulaşılan bu çalışmalar yöntem, kuram, bulgu ve sonuçlar açısından değerlendirilmiştir. Yapılan değerlendirme sonucunda araştırmaya konu olan çalışmaların terapi, danışman eğitimi ve hem terapi hemde danışman eğitimine yönelik olduğu, sinema terapinin uygulama sürecine ilişkin bilgilerin olmadığı ve araştırmaların tamamının doküman analizi yöntemiyle yapıldı̆̆ bulunmuştur. Bunlara ek olarak ülkemizde aile danışmanlığı alanında sinema terapi ile ilgili deneysel bir araştırmaya rastlanmamıştır. Bundan sonra yapılacak çalışmalar için araştırmacılara, film analizi araştırması sırasında bir kuramsal bilgiyi referans almak, deneysel çalışmalar yapmak, sahne, süre, sahnelerin kavramsal karşılı̆̆ını açıkça belirtmek gibi öneriler sunulmuştur. Ülkemizde aile danışmanlığında sinema terapi ile ilgili yapılmış çalışmaları değerlendiren bir çalışmaya rastlanmadı̆̆̆ ve bundan sonra yapılacak çalışmalara bakış açısı olması açısından bu çalışmanın alan yazına ve alan uygulayıcılarına katkı sağlayacağı düşünülmüş̧ür.

Anahtar Kelimeler: Aile terapisi, alan yazın taraması, film analizi, sinema terapi, Türkiye 


\title{
Cinema Therapy: Investigation of Cinema Therapy Studies in Family Counseling
}

\begin{abstract}
This study aims to examine the films used in therapy, family counseling in Turkey in the field of cinema therapy. Document analysis and systematic review methods were used in the research. A total of seven studies meeting the criteria of the study were reached and these studies were evaluated in terms of methods, theories, findings and results. As a result of the evaluation, it was found that the studies subject to the research were directed towards therapy, consultant training and both. There was no information about the practice process of cinema therapy and all the researches were done by document analysis method. In addition, there is no experimental research on cinema therapy in the field of family counseling has been found in Turkey. Researchers for future studies, suggestions were presented to researchers such as reference to a theoretical information during the film analysis research, to conduct experimental studies, to state the stage, duration, and the conceptual equivalent of the scenes. It is thought that there is no study evaluating the studies about cinema therapy in family counseling in Turkey. This study will contribute to the literature and family counselors in terms of having a perspective on the future studies.
\end{abstract}

Keywords: Cinema therapy, family therapy, movie analysis, literature review, Turkey 


\section{Giriş}

Sinema terapi, ruh sağlığı alanında çalışan bir profesyonelin danışanına film izleme ödevi verdiği; karakterleri ve filmde işlenen temaları, danışanın kendisini keşfetmesi ve değişimi teşvik etmesi için metafor olarak kullandığı etkili bir terapötik müdahaledir (Berg-Cross, Jennings ve Baruch, 1990, s. 135; Sharp, Smith ve Cole, 2002, s. 270). Bu tanıma benzer olarak, Gençöz ve Aka (2007)'ya göre, sinema filmlerinin psikoterapi sürecinde müdahale tekniği olarak kullanılmasına sinema terapi denmektedir.

Maratos (2006)'a göre güç, psikoterapide değişime yol açan bir katalizör görevi görür. Sinema terapinin terapötik gücü metaforlara dayanır. Metaforlar, bir kelime veya cümlenin, aralarında bir benzetme önermek için başka birinin yerine kullanıldığı sembollerdir (Merriam-Webster's Online Dictionary, 2020). Bu nedenle sinema terapi, filmlerde bulunan metaforlar, filmdeki karakterler ve davranışlar arasında danışanın yaşadığı problemin benzerliğini göstermektedir. Newton (1995)'a göre bibliyoterapi, danışanın yaşadığ zorlukları daha iyi anlamasına ve başa çıkabilmesine yardım amacıyla, onunki ile benzer yaşam zorluklarıyla uğraşmakta olan kişilerin var olduğu okuma materyalinin önerilmesidir. Sinema terapide de benzer amaçlarla film ve film kesitlerinin izletilmesi ya da ödev olarak verilmesi yoluna gidilir.

Metafor, danışanın psikoterapide değişim, kendini keşfetme ve farkındalık geliştirmek amaciyla tehdit edici olmadıkları ve danışanda savunmaya yol açmadıkları için güçlü bir araç olabilir (Aten, 2004, s. 257; Bailey, 2003, s. 15; Sims, 2003, s. 531). Metaforlar, danışanların kaçınma eğiliminde oldukları kişisel konular hakkında dolaylı olarak danışman-danışan iletişimini güçlendirmek (Nadeau, 2006, s. 215; Wedding ve Niemiec, 2003, s. 212) ve zor kavramların anlaşılması amaçlarıyla kullanılabilir (Rattray, 2004, s. 160). Oaklander (1997)'a göre, gerçek zorlu yaşantıları bir metaforla değerlendirmek bazen daha kolaydır dolayısıyla metaforlar, zor yaşantılarla yüzleşmek için güvenli bir ortam sunabilir; özellikle dirençli, reddeden veya farkındalık düzeyi düşük danışanlar için daha yararlı olabilir.

Psikoterapi alanında pek çok yöntem ve teknik kullanılmaktadır. Sinema filmlerinden de bibliyoterapi tekniği içerisinde yararlanılmaktadır. Bu tekniğin faydalarına ve kullanım alanlarına bakıldığında yayıldığı alanın kayda değer düzeyde olduğu söylenebilir. Sinema filmlerinin kullanıldığı alanlara bakıldığında; bu alanlar, arasında ruh sağlığı (Badura, 2002, s. 58), evlilik ve 
çift terapisi (Shepard ve Brew, 2005, s. 406; Stinchfield, 2006, s. 123), grupla psikolojik danışma (Tyler ve Reynolds, 1998, s. 153) ve çok kültürlülük gibi alanlar yer almaktadır (Shen, 2015, s. 232; Villalba ve Redmond, 2008, s. 264). $\mathrm{Bu}$ alanlar içerisinde psikolojik danışma \psikoterapi alanında Türkiye'de farklı filmlerin kuramlar açısından analiz edildiği çalışmalar (Çağ ve Voltan Acar, 2015, s. 575; Derin ve Voltan Acar, 2016, s. 449; Horzum, 2011, s. 1; Morsümbül, 2015, s. 181; Ormanll, 2011, s. 55; Sakızcioğlu ve Acar, 2016, s. 1288; Ülker Tümlü ve Voltan Acar, 2014, s. 62; Yıldırım, 2011, s. 227) bulunmaktadir.

Bu araştırmanın temel amacı Türkiye'de aile ve evlilik danışmanlığı alanında kullanılan filmlerle ilgili yapılan araştırmaları incelemektir. Bu nedenle yukarıda bahsedilen alanlardan evlilik ve aile danışmanlığı ile ilgili literatürde yapılan sinema terapi araştırmalarına bakıldığında temelde iki açıdan farklılaştıkları görülmektedir. Bu farklılıklardan ilki, yapılan araştırmaların aile danışmanlığı eğitimi (Hudock ve Warden, 2001, s. 116; Maynard, 1996, s. 195) sürecine katkı sağlamak üzere yapıldığı görülmektedir. İkincisi ise ailelere ve çiftlere terapötik müdahale (Dermer ve Hutchings, 2000, s. 163) amacıyla aile ve evlilik danışmanlığı uygulamalarına katkı sağlamak üzere yapıldığı dikkat çekmektedir.

Aile ve evlilik danışmanlığı sürecinde sinema terapi, terapötik müdahale aracı olarak (Schneider, 2000, s. 127) kullanılmaktadır. Bu süreçte terapistler, danışanlara kendilerine verilen filmi terapötik bir lens aracılığıyla nasıl izlemeleri gerektiği konusunda yönergelerle rehberlik ederler (Wedding ve Niemiec, 2003, s. 212). Sinema terapi, filmlerin seçimi, danışana ev ödevi olarak verilmesi ve film yoluyla yaşanan deneyimlerin oturumlar sırasında işlenmesi gibi süreçlerden oluşmaktadır (Sharp, Smith ve Cole, 2002, s. 272). Bu süreçlerde danışanların problemlerine çözümler sağlayabilmekte, gelişimlerini teşvik etmekte ve problemlerini yeniden çerçevelemelerine katkı sağlamaktadır. Ayrıca terapinin en önemli iyileştirici unsurlarından biri olan terapist ve danışan arasındaki terapötik bağın inşasında etkili olmaktadır (Powell, Newgent ve Lee, 2006, s. 248). Film izleme sırasında, danışanların kendi sorunlarına benzer zorluklarla karşılaşan film karakterleri ile özdeşleşmeleri, yaşadıkları zorluklar için destek ve kabul bulmaları, probleme ilişkin farkındalıklarını artırmaları, bilgi edinmeleri ve çözüm(ler) bulmaları amaçlanmaktadır (Lampropoulos ve Spengler, 2005, s. 50). 
Sinema terapi uygulamalarında terapist, danışanın durumuna uygun olan filmi seçer ve ondan ödev olarak bu filmi izlemesini ister. Danışan, filmi izleyip terapi seansına geldiğinde filmden yola çıkarak problem yaratan duygu, düşünce ve davranışlar ele alınır. Filmi izledikten sonra danışanlar, kendi yaşamlarıyla ilgili konuların filmde nasıl işlendiğini danışmanlarla tartışırlar (Sharp, Smith ve Cole, 2002, s. 275). Daha sonra tartışılan bu konuların, danışanın yaşadığı problemlerle paralellikleri ele alınır. Amaç, danışanın kendi yaşadığı problemlere film aracılığı ile yeni ve alternatif bakış açıları geliştirmesidir (Gençöz, 2008, s. 7).

Koch ve Dollardhide (2000)'e göre filmler, insan yaşamını iyi yansıttığı için, insanları anlamak adına da iyi birer örnek oluştururlar. Sinema terapi için; danışanın, yaşamını iyi yansıtabilecek bir film belirlemek, karakterlerle özdeşleşmesine ve problemine ilişkin farkındalık geliştirmesine yardım etmek, filmdeki karakterlerin doğru veya yanlış kararlarından kazanım elde etmesini sağlamak ve probleminin çözümüne ilişkin stratejiler geliştirmesini sağlamak odak konulardır (Powell 2008, s. 16). Bu odak konular çerçevesinde filmler yardımıyla birey yaşadığı olaylara farklı açlardan bakabilmekte, geliştirdiği çözüm yollarının olası sonuçlarını somut bir biçimde gözlemleyebilmektedir (Sharp, Smith ve Cole, 2002, s. 275).

Sinema terapinin psikoterapi açısından kullanımının yanın yanı sıra özel gruplar için de programlar bu bulunmaktadır. Örneğin uzun süreli yatarak tedavi gören veya bakım ihtiyacı olan kişiler için sinema terapi programları oluşturulmuştur. Bu programlar, "MediCinema" adlı özel tasarlanmış sinemalarla çok sayıda hastaya "büyük ekran terapisi" (big screen therapy) sunan bir kuruluşudur (Hill, 2006, s.6). Yine ölümcül hastalıkları olan çocukların hayatlarını filmler ve diğer eğlence araçları yoluyla aydınlatmaya çalışan; çocukları, hastalıklarının bir sonucu olarak hissedebilecekleri korku, acı ve izolasyondan uzaklaştırmayı amaçlayan "Starlight" bir başka programdır (Starlight Children's Foundation, 2020).

İkinci olarak filmlerin aile danışmanlığı/terapisi eğitiminde öğretim aracı olarak kullanıldığı görülmektedir. Nichols ve Schwartz (1991)'a göre aile danışmanlığının öğretilmesi, öğrencilere alandaki teori, teknik, süreç ve araştırmalar hakkında bilgiler verilmesini içerir. Çok boyutlu eğitim süreçlerinde (Gladding, 1994, s. 191) öğrenci, konuyu etkili bir öğrenme yöntemi ile duyarak, izleyerek ve tartışarak incelediği zaman öğrenmenin yüzde 90'lara kadar 
arttığ1 belirtilmektedir (Demirel, 2003, s. 52-63). İyi planlanmış bir derste çoğunlukla şu yöntemler kullanılır: ders anlatımları, grup tartışmaları, dış okumalar, video gösterileri ve rol oynama denemeleri (Gladding, 1994, s. 191).

Bireylerin yaşadığı problemler ve problemlerin yaşanma biçimlerinin hayli fazla ve farklı olduğu göz önüne alındığında danışman eğitimlerinde sinema filmlerinin kullanılması öğrencilerin pek çok danışan problemini henüz meslek yaşantılarında karşılaşmadan öğrenmelerini sağlamaktadır bu da aslında modelden öğrenmenin önemini ön plana çıkarmaktadır. (Bandura ve Walters, 1977, s. 3), öğrenmenin sadece doğrudan deneme yoluyla olması durumunda gelişimin insan yaşamından daha fazla zaman ve enerji gerektireceğini belirtmişlerdir. Bu açıdan bakıldığında sinema terapinin, terapi sürecinde olduğu kadar danışman eğitimi sürecinde de ön plana çıktığı söylenebilir. Eğitim süreçlerinde filmlerden faydalanmak sadece işitsel olarak değil ayn zamanda izleyicinin ilgili bağlamı görsel olarak da kavraması ve değerlendirmesi açısından avantajlı olabilmektedir (Shepard ve Brew, 2005, s. 406). Literatür incelendiğinde, sosyal problemlerden danışmanlık becerilerine kadar uzanan birçok alanın eğitim sürecinde sinema filmlerinin kullanımı ile ilgili kaynaklarla karşlaşmak mümkündür (Dowd, 1999, s. 324; Dressel, 1990, s. 226; Pescosolido, 1990, s. 337; Vinton ve Harrington, 1994, s. 71). Nadir (2014)'e göre, filmlerden görsel olarak faydalanmak, öğrencilerin bilginin yanı sıra beceri ve değer gibi ilkeleri de öğrenmesi açısından oldukça önemlidir. Danışman eğitiminde sinema filmlerinin kullanılması, literatürde savunulan ortak bir deneyimsel öğretim yöntemidir (Koch ve Dollarhide, 2000, s. 203; Pinterits ve Atkinson, 1998, s. 203; Tyler ve Guth, 1999, s. 153). Turns ve Macey, (2015), sinema terapi ile çalışacak terapistlerin uygun filmlerin listesini tutmaları ve danışanların etnik kökenleri ve kültürel farklılıklarının film seçimlerinde dikkate alınması gerektiğini belirtmişlerdir.

Danışman eğitimi sürecinde örnek olay incelemesi olarak da kullanılan filmler, öğrencinin konu ve karakterlerle olan etkileşimini derinleştirebilir ve öğrencinin yakınlık, saygı, sevgi, tiksinme, korku, öfke vb. duyguları hissetmesine, tanımlamasına ve iyileştirmesine katkı sağlayabilir. Filmler, izleyiciyi sıklıkla farklı bir ortama taşıyarak hayal gücünü duyusal ve bilişsel seviyelerde tetikler (Grodal, 1997, s. 6; Lowman, 1984; akt. Pescosolido, 1990, s. 338339). Sinema filmlerindeki sahneler ile aile danışmanlığında kullanılan kavramları eşleştiren Shepard ve Brew (2005)'e göre avantajlarına bakıldığında 
film tabanlı bir ders hazırlamanın harcanan çabaya değeceği söylenebilir. Ayrıca filmlerden daha iyi yararlanmak için, eğitmen filmi izletmeden veya ödev olarak vermeden önce öğrencilere filmin yazılı bir özetini vermek, derste kullanım amacını açıkça anlatmak ve dramatik sahneleri çerçevelemek gibi uygulamalar yapmalıdır (Villalba ve Redmond, 2008, s. 268).

Literatürden yola çıkarak sinema terapinin danışman \terapist eğitimi açısından zaman, konuları somutlaştırma, örneklendirme, öğrenme içeriğinin daha kalıcı olması, dersin daha ilgi çekici hale getirilmesi, danışmanlık becerilerini simüle etmeleri, danışanla terapötik ilişkinin kurulması ve geliştirilmesi gibi pek çok açıdan katkısı olduğu söylenebilir. Terapi \danışmanlık sürecinde ise sinema terapinin, danışanların problemlerine farklı ve objektif bir pencereden bakmaları, perspektifler geliştirmeleri, problemlerini normalleştirmeleri ve çözüm yolları geliştirmeleri gibi katkılar sağladığı söylenebilir. Bütün bunlardan yola çıkarak sinema terapinin bir filmi sıradan bir şekilde izlemekten daha fazlası olduğu söylenebilir.

Bu çalışmada, ülkemizde yapılan aile danışmanlığı alanında film analizini ele almış çalışmaların detaylarının incelenebilmesi için sistematik bir tarama yapılması planlanmıştır. Bu konuda yapılan literatür taramasında ülkemizde, planlanan çalışmaya benzer bir çalışmaya rastlanmamıştır. Böylece ülkemizde aile danışmanlığı alanında gerek danışman eğitiminde gerekse terapi sürecinde kullanılan filmlerin güncel durumu değerlendirilerek ileride yapılacak çalışmalara öneriler sunulması planlanmakta, bu açıdan lüteratüre katkı sağlaması açısından önemli bir çalışma olacağı düşünülmektedir. Filmlerin kullanım ve uygulama alanlarına bakıldığında film analizi çalışmalarının danışma süreci ve eğitim süreci açılarından önemli olduğu görülmektedir. Bu çalışmanın amacı Türkiye'de şu anda var olan film analizi çalışmalarını incelemek, sistemli bir şekilde değerlendirmek ve bundan sonraki yapılacak çalışmalar için öneriler sunmaktır.

\section{Yöntem}

$\mathrm{Bu}$ araştırmada içerik analizi (doküman analizi) ve sistemli tarama yöntemleri kullanılmıştır. İçerik analizi, metinlerin karşılaştırılması, sınıflandırılması, benzer ve farklı yönlerinin belirlenmesi ve metinlerden teorik sonuçlar çıkarılmasından oluşan bir araştırma tekniğidir (Cohen, Manion ve Morrison, 2007, s. 475). Bu çalışmada içerik analizi, bu yönlerin yanı sıra benzer verileri 
bir araya getirerek daha anlaşlır biçime dönüştürmeyi kolaylaştırması nedeniyle tercih edilmiştir (Bauer, 2000, s. 145; Yıldırım ve Şimşek, 2005, s. 217). Sistemli tarama yöntemi, bu araştırma konusu ile ilgili daha önce yapılmış araştırmaları yöntemsel açıdan inceler. Ayrıca önceki çalışmaların bulgularını kapsamlı bir şekilde özetleyerek birbirinden farklı bulguların nedenlerini tartışar ve çalışmaların sınırlılıklarını ortaya koyar (Cook, Mulrow ve Haynes, 1997, s. 378).

Bu tarama ve içerik analizi araştırmasının amacı Türkiye'de aile danışmanlığı alanında yazılmış film analizi makalelerini değerlendirmektir. $\mathrm{Bu}$ amaç doğrultusunda, araştırmaya veri kaynağı olacak araştırmalar belirlenmiştir. Araştırmalara ulaşma süreci aşağıda detaylı bir şekilde sunulmuştur.

\section{Tarama yöntemleri}

Araştırmaya konu olan veri kaynaklarını oluşturan aile danışmanlığında kullanılan film makaleleri, Aralık 2019 ve Ocak 2020 tarihleri arasında taranmıştır. Tarama, Ulakbim, Ebscohost ve Science Direct veri tabanları, Yüksek Öğretim Kurumu Ulusal Tez Merkezi (YÖK-TEZ) ve Google Scholar arama motoru aracılığı ile yapılmıştır. Bu taramalara ek olarak ulaşılan çalışmaların kaynakçaları kontrol edilmiştir.

$\mathrm{Bu}$ çalışmalarla ilgili kapsamlı bir tarama için yukarıda bahsi geçen veri tabanlarında ve arama motorlarında anahtar kelimeler kullanılmıştır. Tarama "aile danışmanlığı, aile terapisi, çift terapisi, film analizi, sinema terapi, sineterapi, film terapisi" anahtar kelimeleri ile yapılmıştır. Ayrıca araştırmaların İngilizce yazılmış olma ihtimali göz önünde bulundurularak "family counselling, family therapy, couple therapy, movie analysis, cinetherapy, film therapy, movie therapy" anahtar kelimeleri ile de tarama yapılmıştır.

Araştırmada veri kaynağı olarak kullanılabilmesi için şu ölçütleri sağlaması belirlenmiştir: (1) Aile danışmanlığı alanında kullanılabilecek konuyu ele alan bir film olması (2) aile danışmanlığı kuramlarından en az birini kuramsal temele alması (3) ele alınan filmin ilgili kuramda kavramsal karşılıklarının olması (4) danışman eğitimi veya terapiye yönelik olması (5) araştırmanın yayınlanmış olması. 


\section{Veri Kaynakları}

Yapılan tarama sonucunda film analizi yapılmış çalışmalar incelendiğinde araştırmanın koşullarını karşılayan yedi adet çalışmaya ulaşılmıştır. Ulaşılan araştırmalar şunlardır;

1. Sembolik-Yaşantısal Aile Terapisi Kuramın referans alan "Ya Sonra" filmi. Özcan Deniz'in yönetmenliğini yaptığı film 2010 yılında yayınlanmış ve dram, komedi ve romantik türlerindedir (Çağ ve Voltan-Acar, 2015).

2. Çok Kuşaklı/Kuşaklararası Aile Terapisi Kuramını referans alan "Babam ve Oğlum” filmi. Çağan Irmak'ın yönetmenliğini yaptığı film 2005 y1lında yayınlanmış ve dram türündedir (Acar ve Voltan-Acar, 2013).

3. Yapisal Aile Terapisi Kuramın referans alan "Dalgaların Prensi (The Prince Of Tides)" filmi. Barbra Streisand'ın yönetmenliğini yaptığı film 1991 yılında yayınlanmış, dram ve romantik türlerindedir (Nadir, 2013).

4. Satir, Minuchin, Bowen ve Haley kuramcilarının kuramların referans alan "Gilbertin Hayalleri (What's Eating Gilbert Grape)" filmi. Lasse Hallström'ın yönetmenliğini yaptığı film 1994 yılında yayınlanmış ve dram türündedir (Bozdağ, 2018).

5. Virginia Satir Aile Terapisi Kuramını referans alan "Annem Uğruna (One True Thing)" filmi. Carl Franklin'in yönetmenliğini yaptı̆̆ film 1998 y1lında yayınlanmış ve dram türündedir (Şenol-Durak ve Fışıloğlu, 2007).

6. Bowlby'nin Çocukluk Dönemi Bağlanma Stilleri ve Minuchin'in Yapısal Aile Sistemleri kuramların referans alan "Kevin Hakkında Konuşmalıyız (We Need To Talk About Kevin)" filmi. Lynne Ramsay'in yönetmenliğini yaptığı film 2011 yılında yayınlanmış ve dram, gizem ve gerilim türlerindedir (Mert ve Soyer, 2014).

7. Yapısal Aile Terapisi Kuramını referans alan "Gelin" filmi. Lütfi Akad'ın yönetmenliğini yaptığı film 1973 yılında yayınlanmış ve dram türündedir (Yildı, 2017).

\section{Bulgular}

Bu araştırmada taranan aile terapisi film analizi çalışmaları hakkında detaylı bilgiler Tablo 1'de verilmiştir. Türkiye'de aile terapisinde sinema terapi araştırmaları göz önüne alındığında, 
A View of the Symbolic-Experiential Family Therapy of Carl Whitaker through Movie Analysis (Çağ ve Voltan-Acar, 2015) adlı çalışmada SembolikYaşantısal Aile Terapisinin rollerin esnekliği, duygusal küntlük, evlilik parçaların bütününden daha farklıdır, gelişim belirtisi olarak patoloji ve terapistin rolü gibi kavramlar açıklanmıştır. İlgili kavramlara karşılık gelen sahne sayısı, süreleri ve ilgili sahnelerin filmde hangi dakikalarda olduğu gibi bilgilere yer verilmemiştir. Çalışma incelendiğinde kavramlara karşıllk gelen sahnelerin betimlenmiş olduğu ve kavramsal olarak Sembolik-Yaşantısal Aile Terapisi için "Ya Sonra" filminin hem aile danışmanlığ 1 hem de danışman eğitimi için kullanılabileceği söylenebilir.

“Babam ve Oğlum" filmi'nin Çok Kuşakl1/Kuşaklararası Aile Terapisi'nin Temel Kavramları Açısından Değerlendirilmesi (Acar, ve VoltanAcar, 2013) adlı çalışmada Çok Kuşaklı/Kuşaklararası Aile Terapisi'nin temel kavramları olan benliğin farklılaşması, üçgenler/üçgen oluşturma, çekirdek ailenin duygusal sistemi, aile yansıtma süreci, duygusal geri çekilme, kuşaklararası geçiş süreci, kardeş durumu, toplumsal gerileme gibi kavramlar açılanmıştır. Kavramlara ek olarak terapide bir teknik olarak kullanılan genogram açıklanmıştır. Ardından filme konu olan ailenin daha iyi anlaşılabilmesi için ailenin genogramı çizilmiş ve Çok Kuşaklı/Kuşaklararası Aile Terapisi'nin temel kavramlarının olduğu 16 sahne değerlendirilmiştir. Çalışma incelendiğinde kavramlara karşılık gelen sahneler açıklanarak filmde hangi dakikalara karşlık geldiği belirtilmiştir. Kavramsal olarak Çok Kuşaklı/Kuşaklararası Aile Terapisi için "Babam ve Oğlum” filmi aile danışmanlığında terapötik bir müdahale aracı olarak kullanılabilir.

Aile Danışmanlığı Eğitimlerinde Popüler Filmlerin Kullanımı ve Yapısal Aile Terapisi Kurami İle Dalgaların Prensi Filminin Analizi (Nadir, 2013) adlı çalışmada Yapısal Aile Terapisi Kuramının temel kavramları olan denge, s1nırlar, koalisyonlar, alt sistemler, hiyerarşi (kuşaklararası ilişki), işlevsel aile yapısı, işlevsel olmayan aile yapısı kavramları açıklanmıştır. İlgili kavramların daha iyi anlaşılması için kavramlara karşılık gelen dokuz sahne değerlendirilmiştir. Çalışma incelendiğinde kavramlara karşılık gelen sahneler açılanmış ve kavramsal olarak "Dalgaların Prensi (The Prince Of Tides)" filminin yapısal aile terapisi kuramının danışman eğitiminde kullanılabileceği söylenebilir. 
Film Analizi Yöntemi İle Aile Terapileri: Gilbert'in Hayalleri (Bozdağ, 2018) adlı çalışmada Satir, Minuchin, Bowen ve Haley kuramcılarının aile terapisinde kullandıkları denge, işlevsellik, duygusal kopma, yansıtma süreci, koalisyon, alt sistemler, hiyerarşi ve nesiller arası örüntü gibi kavramlar ele alınmıştır ve bunlara ek olarak etkilenme tekerleği ve aile haritası teknikleri örneklerle açıklanmıştır. İlgili kavram ve tekniklerin daha iyi anlaşılması için 10 sahne değerlendirilmiştir. Kavramlara karşılık gelen sahneler açıklanarak filmde hangi dakikalara karşılık geldiği belirtilmiştir. Çalışma incelendiğinde "Gilbertin Hayalleri (What's Eating Gilbert Grape)" filminin yukarıdaki kavramları öğretmek için danışman eğitiminde kullanılabileceği söylenebilir.

Film Analizi Yöntemi ile Virginia Satir Aile Terapisi Yaklaşımına Bir Bakış (Şenol-Durak ve Fışıloğlu, 2007) adlı çalışmada Satir Aile Terapisinin temel kavramları olan ailede öz güven, aile içi iletişim, aile dengesi, aile içi duygusal paylaşım, ailede sorunun odaklandığı kişi, ailenin işlevselliği, aile içi iletişim stilleri ve olgunlaşma gibi kavramlar açıklanmıştır. İlgili kavramların daha iyi anlaşılması için kavramlara karşılık gelen yedi sahne değerlendirilmiştir. Çalışma incelendiğinde kavramlara karşılık gelen sahneler açıklanarak filmde hangi dakikalara karşılık geldiği belirtilmiş ve Virginia Satir Aile Terapisi için "Annem Uğruna (One True Thing)" filminin hem aile danışmanlığı hem de danışman eğitimi amacıyla kullanılabileceği söylenebilir.

"Kevin Hakkında Konuşmalıyı" Filminin Bowlby'nin Çocukluk Dönemi Bağlanma Stilleri ve Minuchin'in Yapısal Aile Sistemleri Yaklaşımı Temel Kavramları Kullanılarak Değerlendirilmesi (Mert ve Soyer, 2014) adlı çalışmada, bu araştırmanın konusu ile ilgili olarak Yapısal Aile Terapisi Kuramının temel kavramları olan işlevsel olmayan aileler, sınırlar, alt sistemler, koalisyon ve üçgenleşme gibi kavramları açıklanmıştır. İlgili kavramların daha iyi anlaşılması için kavramlara karşılık 34 sahne değerlendirilmiştir. Çalışma incelendiğinde kavramlara karşılık gelen sahneler açılanarak filmde hangi dakikalara karşılık geldiği belirtilmiş ve Yapısal Aile Terapisi İçin "Kevin Hakkında Konuşmalıyı (We Need To Talk About Kevin)" filminin hem aile danışmanlığı hem de danışman eğitimi amacıyla kullanılabileceği söylenebilir.

Yapısal Aile Terapisi'nin Temel Kavramlarıyla Gelin Filminin İncelenmesi (Yıldız, 2017) adlı çalışmada Yapısal Aile Terapisi Kuramının temel kavramları olan koalisyon, sistemler, sınırlar, kuşaklararası ilişkiler ve hiyerarşi, denge, esneklik, güç fonksiyonel ve fonksiyonel olmayan aileler, geniş aile, kronik hastalığa sahip çocuğu olan aileler, kök ailesinden bağımsızlaşmamış 
evli bireyler gibi kavramları açıklanmıştır. İlgili kavramlara karşılık gelen sahne sayısı, süreleri ve ilgili sahnelerin filmde hangi dakikalarda olduğu gibi bilgilere yer verilmemiştir. Çalışma incelendiğinde kavramlara karşılık gelen sahneler betimlenmiş ve Yapısal aile terapisi için "Gelin" filminin araştırmacılar tarafından ve aile danışmanlığında terapötik bir müdahale aracı olarak kullanılabilir.

Araştırmalara bakıldığında, (1) araştırmaların genellikle aile danışmanlığı sürecinde terapötik müdahale aracı olarak ve danışman eğitiminde kullanılacak şekilde sınıflandırıldığı, (2) iki çalışma (Bozdağ, 2008; Mert ve Soyer, 2014) dışında diğerlerinin sadece bir kuramsal bilgiyi referans aldığı, (3) filmdeki sahneler ile kuramdaki kavramların eşleştirildiği, (4) araştırmaların deneysel özellik barındırmadığı ve sadece doküman analizi yönteminden oluştuğu, (5) iki çalışma (Çağ ve Voltan-Acar, 2015; Yıldız, 2017) dışında diğerlerinin sahnelerle ilgili süre bilgisi verdiği görülmüştür. Bu araştırmada taranan aile danışmanlığında kullanılan filmler ile ilgili yapılan çalışmalar hakkında detaylı bilgiler Tablo 1'de verilmiştir. 
Sinema Terapi: Aile Danışmanlığı Alanında Sinema Terapi Çalışmalarının İncelenmesi

Tablo 1. Bu araştırmada ele alınan çalışmalar

\begin{tabular}{|c|c|c|c|c|c|}
\hline Kaynak & Film adı & Kuramsal altyap1 & Temel kavramlar ve teknikler & Kime yönelik & Sahne Sayısı \\
\hline $\begin{array}{l}\text { Çağ ve } \\
\text { Voltan-Acar } \\
(2015)\end{array}$ & Ya Sonra & $\begin{array}{l}\text { Sembolik-Yaşantısal } \\
\text { Aile Terapisi }\end{array}$ & $\begin{array}{l}\text { Rollerin esnekliği, duygusal küntlük, evlilik parçaların bütününden } \\
\text { daha farklıdır, gelişim belirtisi olarak patoloji, terapistin rolü }\end{array}$ & $\begin{array}{l}\text { Danışan } \\
\text { Danışman }\end{array}$ & Belirtilmemiş \\
\hline $\begin{array}{l}\text { Acar ve } \\
\text { Voltan-Acar } \\
(2013)\end{array}$ & Babam ve Oğlum & $\begin{array}{l}\text { Çok Kuşaklı-Kuşakla- } \\
\text { rarası Aile Terapisi }\end{array}$ & $\begin{array}{l}\text { - Benliğin farklılaşması, üçgenler/üçgen oluşturma, çekirdek ailenin d } \\
\text { uygusal sistemi, aile yansıtma süreci, duygusal geri çekilme, } \\
\text { kuşaklararası geçiş süreci, kardeş durumu, toplumsal gerileme, genogram }\end{array}$ & Danışan & 16 sahne \\
\hline Nadir (2013) & $\begin{array}{l}\text { Dalgaların Prensi } \\
\text { (The Prince of } \\
\text { Tides) }\end{array}$ & Yapısal Aile Terapisi & $\begin{array}{l}\text { Denge, sınırlar, koalisyonlar, alt sistemler, } \\
\text { hiyerarşi (kuşaklararası ilişki), işlevsel ve işlevsel olmayan aile yapısı }\end{array}$ & Danışman & 9 sahne \\
\hline Bozdağ (2018) & $\begin{array}{l}\text { Gilbertin } \\
\text { Hayalleri } \\
\text { (What's Eating } \\
\text { Gilbert Grape) } \\
\end{array}$ & $\begin{array}{l}\text { Satir, Minuchin, B } \\
\text { Bowen ve Haley }\end{array}$ & $\begin{array}{l}\text { Denge, işlevsellik, duygusal kopma, yansıtma süreci, koalisyon, } \\
\text { alt sistemler, hiyerarşi ve nesiller arası örüntü }\end{array}$ & Danışman & 10 sahne \\
\hline $\begin{array}{l}\text { Şenol-Durak } \\
\text { ve } \\
\text { Fişıloğlu (2007) }\end{array}$ & $\begin{array}{l}\text { Annem Uğruna } \\
\text { (One True Thing) }\end{array}$ & Satir Aile Terapisi & \multicolumn{2}{|c|}{$\begin{array}{l}\text { Ailede öz güven, aile içi iletişim, aile dengesi, aile içi duygusal paylaşım, Danışman } \\
\text { ailede sorunun odaklandığı kişi, ailenin işlevselliği, aile içi iletişim stilleri } \\
\text { ve olgunlaşma }\end{array}$} & 7 sahne \\
\hline $\begin{array}{l}\text { Mert ve } \\
\text { Soyer } \\
(2014)\end{array}$ & $\begin{array}{l}\text { Kevin } \\
\text { Hakkında } \\
\text { Konuşmalıyız } \\
\text { (We Need to } \\
\text { Talk About Kevin) }\end{array}$ & $\begin{array}{l}\text { Bowlby } \\
\text { Bağlanma Stilleri } \\
\text { Yapısal Aile Terapisi }\end{array}$ & İşlevsel olmayan aileler, sınırlar, alt sistemler, koalisyon ve üçgenleşme & $\begin{array}{l}\text { Danışan } \\
\text { Danışman }\end{array}$ & 34 sahne \\
\hline Yildız (2017) & Gelin & $\begin{array}{l}\text { Yapisal Aile } \\
\text { Terapisi }\end{array}$ & \multicolumn{2}{|c|}{$\begin{array}{l}\text { Koalisyon, sistemler, sınırlar, kuşaklararası ilişkiler ve hiyerarşi, denge, es- Araştırmacı } \\
\text { neklik, güç fonksiyonel ve fonksiyonel olmayan aileler, geniş aile, kronik Aile danışman- } \\
\text { hastalığa sahip çocuğu olan aileler, kök ailesinden bağımsızlaşmamış evli ları } \\
\text { bireyler }\end{array}$} & Belirtilmemiş \\
\hline
\end{tabular}




\section{Tartışma ve Sonuç}

Aile danışmanlığında kullanılan filmlere bakıldığında aile danışmanlığı eğitiminin; aile ve evlilik danışmanlığı uygulamaları, danışman eğitimi ve aile danışmanlığı sürecine katkı sağlamak üzere 3 farklı sınıflamada literatür bilgisi olduğu görülmektedir. Bunlardan Acar ve Voltan-Acar (2013)'ın çalışmasının terapi sürecinde kullanıma yönelik; Nadir (2013), Bozdağ (2018) ve Şenol-Durak ve Fışıloğlu (2007) çalışmalarının danışman eğitimine yönelik; Çağ ve Voltan-Acar (2015), Mert ve Soyer (2014) çalışmalarının ise hem danışma sürecine hem de danışman eğitimine yönelik olduğu görülmüştür. Son olarak Yıldız (2017)'ınn çalışmasının ise araştırmacılara ve aile danışmanlarına yönelik bir çalışma olduğu görülmüştür.

Yapılan çalışmalar göz önüne alındığında gerek terapi gerekse danışman eğitimine yönelik yapılan araştırmaların herhangi bir bölümünde uygulama sürecine ilişkin bir bilgi ve bununla ilgili değerlendirmeler içermediği sadece sonuç kısmında hangi amaçla kullanılabileceğine dair bilgiye yer verdikleri görülmüştür. Bu yönüyle yapılan çalışmaların sınırlı olduğu, bundan sonra yapılacak çalışmaların süreç bilgisini daha belirgin bir şekilde yansıtmaları önerilebilir. Bu makalede ele alınan çalışmalar dışında Gençöz, (2008); Boyacı ve İlhan, (2016) ve Uçak-Şimşek, (2003) çalışmalarında uygulama süreçlerinin nasıl olması gerektiğini belirtmişlerdir.

Araştırma kapsamında taranan çalışmalar kuramsal altyapı olarak, Sembolik-Yaşantısal Aile Terapisi (Çağ ve Voltan-Acar, 2015, s. 575), Çok Kuşaklı/Kuşaklararası Aile Terapisi (Acar, ve Voltan-Acar, 2013, s. 37), Yapısal Aile Terapisi (Mert ve Soyer, 2014, s. 102; Yıldız, 2017, s. 159; Nadir, 2013, s. 129), Satir, Minuchin, Bowen ve Haley (Bozdağ, 2018, s. 88), Virginia Satir Aile Terapisi Yaklaşımı (Şenol-Durak ve Fışıloğlu, 2007, s. 43) kuramlarını almışlardır. Çalışmalar her ne kadar farklı kuramsal altyapıları ele alsalar da çoğunlukla Yapısal Aile Terapisi Kuramını (Mert ve Soyer, 2014; Yıldız, 2017; Nadir, 2013) referans aldıkları gözlenmiştir. Bu nedenle bundan sonra yapılacak çalışmalarda aile süreçlerini konu alan filmlerin farklı kuramlar çerçevesinde de değerlendirilmesi önerilebilir. Bozdağ (2018), ise diğerlerinden farklı olarak çalışmasında birden fazla kuramdan yola çıkarak sadece kavram ve teknik açısından film analizi yapmıştır. Birden fazla kuramla ilerlemek ilgili kuramsal bilgiyi öğrenmeyi ve uygulamayı zorlaştırabilir, bu sebeple 
bundan sonra yapılacak çalışmalarda sadece bir kuramsal temeli referans almanın önemli olacağı düşünülmektedir.

Bu araştırmaya konu olan çalışmalara bakıldığında tüm araştırmaların nitel araştırma olup doküman analizi yöntemini kullandıkları görülmüştür. Ancak bu araştırmanın kapsamı dışındaki çalışmalara bakıldığında Eğeci (2010), Aka ve Gençöz (2010), Uçak-Şimşek (2003) ve Pur (2009)'un çalışmalarının sinema terapi alanında ülkemizde yapılmış olan deneysel çalışma özelliğini barındırdıkları da görülmüştür ve bu yönüyle sinema terapi alanında önemli çalışmalar olduğu söylenebilir. Ancak ülkemizde aile terapisi alanında sinema terapiyi ele alan araştırmalarda deneysel çalışmaya rastlanamamıştır. Bundan sonra yapılacak çalışmalarda sinema terapi konusunda aile danışmanlığında deneysel çalışmaların yapılması önerilebilir.

Film sahnelerine denk gelen kavramsal karşılıklar açısından incelendiğinde Çağ ve Voltan-Acar (2015), Acar ve Voltan-Acar (2013), Mert ve Soyer (2014) ve Yıldız (2017)'ın çalışmalarında hangi sahnelerin hangi kavramsal karşılığı olduğu betimlenmiş olduğu ancak filmde hangi dakikalara karşılık geldiğinin açıkça belirtilmemiş olduğu görülmektedir. Nadir (2013), Bozdağ (2018), Şenol-Durak ve Fişıloğlu (2007)'nun çalışmalarında ise filmde hangi kavramların hangi sahnede karşılıkları olduğu açıkça belirtilmiştir. Hass (1995), sinema terapi olarak filmleri izlemeden önce filmi seyrederken hangi sahnelere, hangi kişi ve konulara odaklanılması gerektiğini vurgulamıştır. Sahne, süre, kavramsal karşılık gibi noktaların önceden bilinmesi sinema terapi açısından oldukça önemlidir. Bu nedenle bundan sonra yapılacak olan çalışmalarda bu bilgilerin açıkça belirtilmesi önerilebilir.

Son olarak ülkemizde sinema terapinin aile danışmanlığı alanında kullanımı ile ilgili yapılan bilimsel araştırmaların oldukça az olduğu görülmüştür. Bu durumun uygulama açısından standart bir model oluşamamasına yol açtığı söylenebilir. Bundan sonra aile danışmanlığı konusunda sinema terapi kullanımını farklı kuramsal temellerle, farklı örneklem gruplarıyla ele alan çalışmaların yapılmasının ve bu çalışmaların artmasının literatüre önemli katkılar sağlayacağı açıktır. 


\section{EXTENDED ABSTRACT}

\section{Cinema Therapy: Investigation of Cinema Therapy Studies in Family Counseling \\ * \\ Ferhat Bayram - Eyyüp Özkamalı \\ Ministry of National Education, Gaziantep University}

Cinema therapy, a professional working in the field of mental health, gave the film to the client to watch movies; it is an effective therapeutic intervention used by characters and themes in the film as metaphors for clients' to discover themselves and promote change(Berg-Cross, Jennings and Baruch, 1990, p. 135; Sharp, Smith and Cole, 2002, p. 270). According to Maratos (2006), power acts as a catalyst that causes change in psychotherapy. The therapeutic power of cinema therapy is based on metaphors. Metaphors are symbols where a word or phrase is used instead of another to suggest an analogy between them (Merriam-Webster's Online Dictionary, 2020). For this reason, cinema therapy shows the likeness of the client's problem between the metaphors in the movies, the characters and behaviors in the movie. According to Oaklander (1997), sometimes it is easier to evaluate real tough experiences with a metaphor, so metaphors can provide a safe environment to face tough situations; may be particularly useful for resistant, refusing, or low awareness clients.

In the field of psychotherapy in Turkey, there are studies that were analyzed in terms of different theories movies (Çağ and Voltan Acar, 2015, p. 575; Derin and Voltan Acar, 2016, p. 449; Horzum, 2011, p. 1; Morsümbül, 2015, p. 181; Ormanlı, 2011, p. 55; Sakızcıoğlu and Acar, 2016, p. 1288; Ülker Tümlü \& Voltan Acar, 2014, p. 62; Yıldırım, 2011, p. 227). This study main objective to examine the researches done on the movies in family and marriage counseling in Turkey. Therefore, when look at the cinema therapy researches in the literature on marriage and family counseling from the above-mentioned fields, it can be seen that they differ from two aspects basically. Firstly, it is seen that the researches are made to contribute to the family counseling education process (Hudock and Warden, 2001, p. 116; Maynard, 1996, p. 195). Secondly, 
it is noteworthy that it was made to contribute to family and marriage counseling practices for therapeutic intervention for families and couples (Dermer and Hutchings, 2000, p. 163).

Cinema therapy consists of choosing a movie, giving it to the client as homework, and processing the experiences through the film during the sessions (Sharp, Smith and Cole, 2002, p. 272). This process can provide clients with solutions to their problems, promote their development and contribute to framing their problems. It is also effective in the construction of the therapeutic relationship between the therapist and the client, one of the most important healing component of therapy (Powell, Newgent and Lee, 2006, p. 248).

In terms of consultant / therapist training, cinema therapy can be said to contribute in many aspects such as concretioning the subjects, sampling, learning content is more permanent, making the course more interesting, simulating counseling skills, establishing and developing the therapeutic relationship with the client. Therapy / counseling process, it can be said that cinema therapy contributes to the clients' problems such as looking through a different and objective side, developing perspectives, normalizing their problems and developing solutions. Based on these, it can be said that cinema therapy is more than just watching a movie in an ordinary way.

The aim of this study examine of the film analysis of research in Turkey, in a systematic way to evaluate and to provide recommendations for future studies. In order to be used as a data source in the research, the following criteria have been determined: (1) Being a movie that deals with the subject that can be used in the field of family counseling. (2) Taking at least one family counseling theory on a theoretical basis. (3) The film has conceptual responses in the relevant theory. (4) Being directed towards counselor education or clients. (5) Research being published. As a result of the screening, seven studies meeting the conditions of the research were reached. These studies,

1. The movie "Ya Sonra" referring to the Symbolic-Experiential Family Therapy Theory (Çağ and Voltan-Acar, 2015).

2. The movie "Babam ve Oğlum" referring to the Multi-generational / Intergenerational Family Therapy Theory (Acar and Voltan-Acar, 2013).

3. The movie "Prince of Tides" based on Structural Family Therapy Theory (Nadir, 2013).

4. The movie "What's Eating Gilbert Grape", which references the theories of Satir, Minuchin, Bowen and Haley theorists (Bozdağ, 2018). 
5. The movie "One True Thing" movie (Şenol-Durak and Fişıloğlu, 2007), which reference Virginia Satir Family Therapy Theory.

6. The movie "We Need To Talk About Kevin", based on Bowlby's Childhood Attachment Styles and Minuchin's Structural Family Systems theories (Mert and Soyer, 2014).

7. The movie "Gelin", based on Structural Family Therapy Theory (Yildız, 2017).

Consequently, when the researches are examined, (1) researches are generally classified as a therapeutic intervention in the family counseling process and to be used in counselor education, (2) except for two studies (Bozdağ, 2008; Mert and Soyer, 2014), others refer to only one theoretical knowledge, (3) where the scenes in the movie and the concepts in theory are matched, (4) research has not an experimental feature and only consists of document analysis method, (5) except for two studies(Çağ and Voltan-Acar, 2015; Yıl$\mathrm{d} 1 \mathrm{z}, 2017)$, it was seen that others gave time information about the scenes. Finally, it has been observed that there is a limited number of scientific researches on the use of cinema therapy in the field of family counseling in Turkey. It can be said that this situation leads to the lack of a standard model in terms of practice. It is clear that the studies on the use of cinema therapy on family counseling with different theoretical foundations and different sample groups and the increase of these studies will contribute to the literature.

\section{Kaynakça / References}

Acar, T., ve Voltan-Acar, N. (2013). Babam ve Oğlum" filminin çok kuşaklı/kuşaklararası aile terapisinin temel kavramları açısından değerlendirilmesi. Kuram ve Uygulamada Eğitim Bilimleri, 13(1), 37-53.

Aka, B. T., ve Gençöz, F. (2010). Sinematerapinin Mükemmeliyetçilik ve Mükemmeliyetçilikle Ilgili Semalar Üzerindeki Etkisi. Türk Psikoloji Dergisi, 25(65), 69.

Aten, J. D. (2004). The Rubik's cube: A therapeutic metaphor. Journal of Psychology and Christianity, 23, 258-260.

Badura, A. S. (2002). Capturing students' attention: Movie clips set the stage for learning in abnormal psychology. Teaching of Psychology, 29(1), 58-60.

Bailey, L. W. (2003). Modeling the Master: Effective use of metaphor in Christian counseling. Longwood, FL: Xulon Press.

Bandura, A., ve Walters, R. H. (1977). Social learning theory (Vol. 1). Englewood Cliffs, NJ: Prentice-hall. 
Bauer, M. W. (2000). Classical content analysis: A review. Qualitative researching with text, image and sound, 131-151. doi:10.4135/9781849209731.n8

Berg-Cross, L., Jennings, P., ve Baruch, R. (1990). Cinematherapy: Theory and application. Psychotherapy in Private Practice, 8, 135-156. doi:10.1300/J294v08n01_15

Boyac M., ve İlhan, T. (2016). Bilişsel davranışçı terapi yaklaşımının film analizi yöntemiyle incelenmesi.Mersin Üniversitesi Ĕ̆gitim Fakültesi Dergisi,12(2). doi:10.17860/efd.03838

Bozdağ, Y. (2018). Film analizi yöntemi ile aile terapileri: Gilbert'in Hayalleri. Yaşam Becerileri Psikoloji Dergisi, 2(3), 87-95. doi:10.31461/ybpd.430396

Cohen, L., Manion, L., ve Morrison, K. (2013). Experiments, quasi-experiments, single-case research and internet-based experiments. Research Methods in Education içinde (s. 336-358). Routledge.

Cook, D. J., Mulrow, C. D., ve Haynes, R. B. (1997). Systematic reviews: synthesis of best evidence for clinical decisions. Annals of internal medicine, 126(5), 376-380. doi:10.7326/0003-4819-126-5-199703010-00006

Çağ, P. ve Voltan Acar, N. (2015). A view of the symbolic-experiential family therapy of Carl Whitaker through movie analysis. Educational Sciences: Theory and Practice, 15(3), 575-586. doi:10.12738/estp.2015.3.2477

Demirel, Ö. (2003). Planlamadan değerlendirmeye öğretme sanatı (5. baskı). Ankara: PegemA Yayıncilik.

Derin, S. ve Voltan Acar, N. (2016). Analitik terapi bağlamında film analizi: Tehlikeli ilişki. Journal of International Social Research, 9(45), 449-460.

Dermer, S. B., ve Hutchings, J. B. (2000). Utilizing movies in family therapy: Applications for individuals, couples, and families. The American Journal of Family Therapy, 28(2), 163-180. doi:10.1080/019261800261734

Dowd, J. J. (1999). Waiting for Louis Prima: On the possibility of a sociology of film. Teaching Sociology, 324-342. doi:10.2307/1319040

Dressel, P. (1990). Films that put social problems in global context. Teaching Sociology, 18(2), 226-230. doi:10.2307/1318496

Eğeci, İ. S., (2010). Utilizing cinematherapy to improve relationship satisfaction: A qualitative study. Doktora tezi. Orta Doğu Teknik Üniversitesi, Ankara.

Gençöz, F. (2008). Sinema filmlerinde intihar: Araştırma, eğitim ve sinematerapi. Kriz Dergisi, 16(2), 1-10. doi:10.1501/Kriz_0000000272

Gençöz, F. ve Aka, B. T. (2007). Sinema tadında terapi: Sinematerapi. Bilim ve Teknik, $473,58-61$. 
Gladding, S. T. (1994). Teaching family counseling through the use of fiction. Counselor Education and Supervision, 33(3), 191-200. doi:10.1002/j.15566978.1994.tb00285.x

Grodal, T. K. (1997). Moving pictures. A new theory of film genres, feelings and cognition. Claredon/Oxford Univ. Press

Haas, J. W. (1995). The application of cinema in the practice of psychology. Dissertation Abstracts International: Section B: The Sciences and Engineering, 5(5).

Hill, B. (2006). Cinematherapy: Moving pictures. Hospital Development, 1, 6-7.

Horzum, I. (2011). 'Dövüş Kulübü' filminin ruhbilimsel çözümlemesi. Akademik Bakış Dergisi, 25, 1-24.

Hudock Jr, A. M., ve Warden, S. A. G. (2001). Using movies to teach family systems concepts. The Family Journal, 9(2), 116-121. doi:10.1177/1066480701092005

Koch, G., ve Dollarhide, C. T. (2000). Using a popular film in counselor education: Good Will Hunting as a teaching tool. Counselor Education and Superoision, 39(3), 203-210. doi:10.1002/j.1556-6978.2000.tb01232.x

Lampropoulos, G. K., ve Spengler, P. M. (2005). Helping and change without traditional therapy: Commonalities and opportunities. Counselling Psychology Quarterly, 18(1), 47-59. doi:10.1080/09515070500099629

Lowman, J. ve Lowman, J. (1984). Mastering the techniques of teaching (Vol. 1990). San Francisco: Jossey-Bass.

Maratos, J. (2006). The power of myth as metaphor. Group Analysis, 39(1), 87-99. doi:10.1177/0533316406062089

Maynard, P. E. (1996). Teaching family therapy theory: Do something different. American Journal of Family Therapy, 24(3), 195-205. doi:10.1080/01926189608251033

Merriam-Webster's Online Dictionary. (2020, 10 Şubat). https://www.merriam-webster.com/dictionary/metaphor adresinden erişilmiştir.

Mert, A., ve Soyer, B. (2014). “Kevin Hakkında Konuşmalıyız" Filminin Bowlby’nin çocukluk dönemi bağlanma stilleri ve minuchin'in yapısal aile sistemleri yaklaşımı temel kavramları kullanılarak değerlendirilmesi. OPUS Uluslararası Toplum Araştırmaları Dergisi, 4(7), 100-115.

Morsümbül, Ü. (2015). Bal, Süt ve Yumurta filmlerinin Erikson'un psikososyal gelişim kuramı açısından analizi. İlköğretim Online, 14(1), 181-187.

Nadeau, J. W. (2006). Metaphorically speaking: The use of metaphors in grief therapy. Illness, Crisis \& Loss, 14(3), 201-221. doi:10.1177/105413730601400301

Nadir, U. (2013). Aile danişmanliği eğitimlerinde popüler filmlerin kullanimi ve yapisal aile terapisi kurami ile Dalgalarin Prensi filminin analizi. Toplum ve Sosyal Hizmet, 24(1), 129-144. 
Nadir, U. (2014). Benefiting from the popular films integrated into the curriculum in boosting the efficacy of the social work education. Procedia-Social and Behavioral Sciences, 152, 313-317. doi:10.1016/j.sbspro.2014.09.201

Newton, A. K. (1995). Silver screens and silver linings: Using theater to explore feelings and issues. Gifted Child Today, 18(2), 14-43. doi:10.1177/107621759501800206

Nichols, M. P., ve Schwartz, R. C. (1991). Family therapy (2nd ed.). Boston, MA: Allyn \& Bacon.

Oaklander, V. (1997). The rosebush. In H. Kaduson and C. Schaefer (Eds.), 101 favorite play therapy techniques (p. 11-13). Northvale, NJ: Aronson.

Ormanl, O. (2011). Başlangıç filminde psikoanalitik ögeler ve rüya olgusu. Dokuz Eylül Üniversitesi Güzel Sanatlar Fakültesi Dergisi, 6, 55-62.

Pescosolido, B. A. (1990). Teaching medical sociology through film: theoretical perspectives and practical tools. Teaching Sociology, 337-346. doi:10.2307/1317736

Pinterits, E. J., ve Atkinson, D. R. (1998). The diversity video forum: An adjunct to diversity sensitivity training in the classroom. Counselor Education and Supervision, 37(3), 203. doi:10.1002/j.1556-6978.1998.tb00545.x

Powell, M. L. (2008). Cinematherapy as a clinical intervention: Theoretical rationale and empirical credibility. Doctoral dissertation. University of Arkansas, Arkansas.

Powell, M. L., Newgent, R. A., ve Lee, S. M. (2006). Group cinematherapy: Using metaphor to enhance adolescent self-esteem. The arts in psychotherapy, 33(3), 247253. doi:10.1016/j.aip.2006.03.004

Pur, İ. G. (2009). Cinematherapy for alcohol dependent patients.Yayımlanmamış yüksek lisans tezi). Ortadoğu Teknik Üniversitesi, Ankara.

Rattray, S. L. (2004). The use of metaphor. In J. Swartz (Ed.), The marriage clinic casebook (p. 155-163). New York: W.W. Norton \& Co.

Sakızcıoğlu, S. ve Voltan Acar, N. (2016). Uzak filminin varoluş̧̧u terapinin temel kavramları açısından değerlendirilmesi. Journal of International Social Research, 9(43), 1288-1297.

Schneider, I. (2000). Rent two films and let's talk in the morning: Using popular movies in psychotherapy. Bulletin of the Menninger Clinic, 64(1), 127.

Sharp, C, Smith, J. V., ve Cole, A. (2002). Cinematherapy: Metaphorically promoting therapeutic change. Counseling Psychology Quarterly, 15(3), 269-276. doi:10.1080/09515070210140221

Shen, Y. J. (2015). Cultivating multiculturally competent counselors through movies. Journal of Creativity in Mental Health, 10(2), 232-246. doi:10.1080/15401383.2014.959679 
Shepard, D. S., ve Brew, L. (2005). Teaching theories of couples counseling: The use of popular movies. The family journal, 13(4), 406-415. doi:10.1177/1066480705278470

Sims, P. A. (2003). Working with metaphor. American journal of psychotherapy, 57(4), 528-536. doi:10.1176/appi.psychotherapy.2003.57.4.528

Snider, M. (1992). Processfamily therapy. Boston, MA: Allyn \& Bacon.

Starlight Children's Foundation. (2020, 10 Şubat). https://www.starlight.org.uk/whatwe-do/starlight-escapes/adresinden erişilmiştir.

Stinchfield, T. A. (2006). Using popular films to teach systems thinking. The Family Journal, 14(2), 123-128. doi:10.1177/1066480705285559

Şenol-Durak, E., ve Fışıloğlu, H. (2007). Film analizi yöntemi ile Virginia Satir aile terapisi yaklaşımına bir bakış. Türk Psikoloji Yazıları, 10(20), 43-62.

Turns, B., \& Macey, P. (2015). Cinema narrative therapy: utilizing family films to externalize children's 'problems'. Journal of Family Therapy, 37(4), 590-606. doi:doi.org/10.1111/1467-6427.12098

Tyler, J. M., ve Guth, L. J. (1999). Using media to create experiential learning in multicultural and diversity issues. Journal of Multicultural Counseling and Development, 27(3), 153-169. doi:10.1002/j.2161-1912.1999.tb00221.x

Tyler, J. M., ve Reynolds, T. (1998). Using feature films to teach group counseling. Journal for specialists in group work, 23(1), 7-21. doi:10.1080/01933929808411378

Uçak-Simsek, E. (2003). Bilissel davranisçi yaklasimla ve rol degistirme teknigiyle bütünlestirilmis film terapisi uygulamasinin islevsel olmayan düsüncelere ve iyimserlige etkisi. Yayimlanmamis doktora tezi. Ankara Üniversitesi, Ankara.

Ülker Tümlü, G. ve Voltan Acar, N. (2014). “Issız Adam” filminin gerçeklik terapisine dayalı incelenmesi. İnsan ve İnsan, 2, 62-73. doi:10.29224/insanveinsan.279983

Villalba, J. A., ve Redmond, R. E. (2008). Crash: Using a popular film as an experiential learning activity in a multicultural counseling course. Counselor Education and Supervision, 47(4), 264-276. doi:10.1002/j.1556-6978.2008.tb00056.x

Vinton, L., ve Harrington, P. (1994). An evaluation of the use of videotape in teaching empathy. Journal of Teaching in Social Work,9(1-2), 71-84. doi:10.1300/J067v09n01_06

Wedding, D., ve Niemiec, R. M. (2003). The clinical use of films in psychotherapy. Journal of clinical psychology, 59(2), 207-215. doi:10.1002/jclp.10142

Yıldırım, A., ve Şimşek, H. (2005). Sosyal bilimlerde nitel araştırma yöntemleri. Ankara: Seçkin Yayınclık. 
Yıldırım, T. E. (2011). Pedagojik korku sineması: Vampir ve Kurt Adam filmlerine psikoseksüel ve psikososyal gelişim basamakları açısından bir bakış. G.Ü. İletişim Fakültesi Illetişim Kuram ve Araştırma Dergisi, 32, 227-242

Yıldız, M. (2017). Yapısal aile terapisi'nin temel kavramlarıyla gelin filminin incelenmesi.OPUS Uluslararası Toplum Araştırmalarn Dergisi,7(12), 157-176. doi:10.26466/opus.285054

\section{Kaynakça Bilgisi / Citation Information}

Bayram, F. ve Özkamalı, E. (2020). Sinema terapi: Aile danışmanlığı alanında sinema terapi çalışmalarının incelenmesi. OPUS-Uluslararası Toplum Araştırmaları Dergisi, 16(28), 1319-1341. DOI: 10.26466/opus.687535 